\title{
LncRNA-LET inhibits cell growth of clear cell renal cell carcinoma by regulating miR-373-3p
}

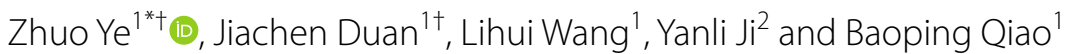

\begin{abstract}
Background: Clear cell renal cell carcinoma (ccRCC) is the most common renal cell carcinoma subtype with a poor prognosis. LnCRNA-LET is a long non-coding RNA (InCRNA) that is down-regulated in cCRCC tissues. However, its role in cCRCC development and progress is unclear.

Methods: LnCRNA-LET expression was detected in cCRCC tissues and CCRCC cells using quantitative real-time PCR. The overexpression and knockdown experiments were performed in ccRCC cells and xenograft mouse model to evaluate role of IncRNA-LET. Cell cycle, apoptosis and JC-1 assays were conducted via flow cytometer. The protein levels were measured through western blot analysis and the interaction between InCRNA-LET and miR-373-3p was identified via luciferase reporter assay.

Results: LncRNA-LET expression was lower in ccRCC tissues than that in the matched adjacent non-tumor tissues $(n=16)$. In vitro, IncRNA-LET overexpression induced cell cycle arrest, promoted apoptosis and impaired mitochondrial membrane potential, whereas its knockdown exerted opposite effects. Moreover, we noted that IncRNA-LET may act as a target for oncomiR miR-373-3p. In contrast to IncRNA-LET, miR-373-3p expression was higher in ccRCC tissues. The binding between InCRNA-LET and miR-373-3p was validated. Two downstream targets of miR-373-3p, Dickkopf-1 (DKK1) and tissue inhibitor of metalloproteinase-2 (TIMP2), were positively regulated by InCRNA-LET in cCRCC cells. MiR-373-3p mimics reduced IncRNA-LET-induced up-regulation of DKK1 and TIMP2 levels, and attenuated IncRNALET-mediated anti-tumor effects in CCRCC cells. In vivo, InCRNA-LET suppressed the growth of CCRCC xenograft tumors.
\end{abstract}

Conclusion: These findings indicate that InCRNA-LET plays a tumor suppressive role in CCRCC by regulating miR-373-3p.

Keywords: Clear cell renal cell carcinoma, LncRNA-LET, miR-373-3p, Cell cycle, Cell apoptosis

\section{Background}

Renal cell carcinoma (RCC), as one of most frequent cancers worldwide, is a common lethal malignancy $[1,2]$. RCC incidence and death rates are high, with 63,000 new cases and 14,000 deaths per year in United States [3]. Surgical resection and immunotherapy are currently being applied to treat patients with RCC [4-6]. RCC includes more than 10 histological and molecular subtypes [7],

\footnotetext{
*Correspondence: neoneyz@126.com

${ }^{\dagger}$ Zhuo Ye and Jiachen Duan contributed equally to this study

${ }^{1}$ Department of Urology, The First Affiliated Hospital of Zhengzhou University, 1 East Jianshe Road, Zhengzhou 450052, People's Republic of China

Full list of author information is available at the end of the article
}

with clear cell RCC (ccRCC) as the most common subtype [8]. The detailed molecular mechanisms underlying ccRCC development remain elusive.

Non-coding RNAs (ncRNAs) are found to be important players in epigenetic regulation, especially long ncRNAs ( $>200$ nucleotides, lncRNAs) and microRNAs ( $<22$ nucleotides, miRNAs) [9-11]. Emerging evidence indicates that numerous dysregulated IncRNAs are involved in the development and progression of ccRCC $[12,13]$. LncRNA-LET, as a recently identified IncRNA, was located at chromosome $15 \mathrm{q} 24.1[11,14]$, and it plays a suppressive role in regulating cancer cell growth in malignancies, including esophageal squamous cell carcinoma and lung adenocarcinoma [14-16]. In ccRCC, the

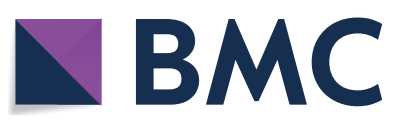

(c) The Author(s) 2019. This article is distributed under the terms of the Creative Commons Attribution 4.0 International License (http://creativecommons.org/licenses/by/4.0/), which permits unrestricted use, distribution, and reproduction in any medium, provided you give appropriate credit to the original author(s) and the source, provide a link to the Creative Commons license, and indicate if changes were made. The Creative Commons Public Domain Dedication waiver (http://creativecommons.org/ publicdomain/zero/1.0/) applies to the data made available in this article, unless otherwise stated. 
role that lncRNA-LET plays is unknown. Interestingly, lncRNA-LET expression is low in serum samples from patients with ccRCC [17], suggesting its involvement in the carcinogenesis of this cancer.

Previous studies have shown that IncRNA-LET has the potential to target miRNAs, thereby regulating the expression of miRNA targets to affect the process of human cancers $[18,19]$. Although varied miRNAs may be regulated by lncRNA-LET, we here focused on miR373-3p. Both tumor-promoting and anti-tumor effects of miR-373-3p have been reported before [20, 21]. An earlier study has revealed that miR-373-3p acts as an oncomiR in RCC [22]. By analyzing the sequence information of lncRNA-LET and miR-373-3p, we noted that lncRNA-LET contained a potential binding area for miR373-3p. This study is thus performed to explore whether lncRNA-LET regulates the malignant behaviors of ccRCC cells by regulating miR-373-3p.

Herein, we explored the specific role of lncRNA-LET in regulating ccRCC growth in vitro and in vivo. LncRNALET overexpression or knockdown was performed in ccRCC cells. Meanwhile, the xenograft mouse model was constructed. We demonstrated that lncRNA-LET suppressed the growth of ccRCC cells. LncRNA-LETinduced cell cycle arrest and apoptosis in ccRCC cells were attenuated by miR-373-3p mimics.

\section{Materials and methods \\ Patients and tissues}

The human ccRCC and matched adjacent non-tumor tissues were obtained from $16 \mathrm{ccRCC}$ patients from the First Affiliated Hospital of Zhengzhou University during September 2018-November 2018. Each patient provided an informed consent prior to specimen collection. This study was approved by the Ethics Committee of the First Affiliated Hospital of Zhengzhou University, and conferred to Declaration of Helsinki.

\section{Cell culture and transfection}

The ccRCC cell lines (Caki-1, 786-O, 769-P) and 293T cell line were purchased from Procell Life Science \& Technology Co,. Ltd. (Wuhan, China). Caki-1 cells were cultured in McCoy's 5A medium (Procell Life Science \& Technology Co,. Ltd) containing $10 \%$ fetal bovine serum (FBS; Biological Industries, Kibbutz Beit-Haemek, Israel), 786-O and 769-P cells were cultured in RPMI-1640 medium (Procell Life Science \& Technology Co,. Ltd.) supplemented with $10 \% \mathrm{FBS}$, and $293 \mathrm{~T}$ cells were grown in DMEM medium (Procell Life Science \& Technology Co,. Ltd.) containing $10 \% \mathrm{FBS}$ in an incubator at $37{ }^{\circ} \mathrm{C}$ and $5 \% \mathrm{CO}_{2} .786-\mathrm{O}$ cells were transiently transfected with lncRNA-LET overexpression (lncRNA-LET OV), negative control (OV NC) vector, miR-373-3p inhibitor or negative control inhibitor (inhibitor NC), whereas 769-P cells were transiently transfected with lncRNALET siRNA, siRNA NC, miR-373-3p mimics or negative control mimics (mimics $\mathrm{NC}$ ). In addition, 786-O cells were co-transfected with lncRNA-LET OV and miR373-3p mimics or mimics NC. The miR-373-3p inhibitor, inhibitor NC, miR-373-3p mimics and mimics NC were purchased from JTSBIO (Wuhan, China). Further, 786-O cells stably transfected with lncRNA-LET overexpression (lncRNA-LET) or empty control (EV), 769-P cells stably transfected with lncRNA-LET knockdown (lncRNA-LET shRNA) or control (shRNA Ctrl) were established by

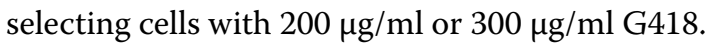

\section{Plasmid construction}

The pcDNA3.1 and pRNAH1.1 vectors were purchased from GenScript (Nanjing, China). To overexpress lncRNA-LET, pcDNA3.1-lncRNA-LET was constructed by GenScript (Nanjing, China). The lncRNA-LET siRNAs and siRNA NC were purchased from JTSBIO (Wuhan, China). The shRNA targeting lncRNA-LET was designed and synthesized, and then cloned into pRNAH1.1 vector to generate the shRNA against lncRNA-LET (lncRNA-LET shRNA). The sequences of IncRNA-LET siRNA-1, IncRNA-LET siRNA-2 and lncRNA-LET shRNA were listed in Table 1.

\section{Quantitative real-time PCR}

Total RNAs were extracted using RL reagent (BioTeke, China). The mRNA was reversely transcribed into complementary DNA with M-MLV Reverse Transcriptase (Takara, China). The expression levels of lncRNA-LET and miR-373-3p were detected via SYBR Green (BioTeke, China). $\beta$-actin and U6 were applied as internal controls. The relative expression levels were calculated with the $2^{-}$ $\Delta \Delta \mathrm{Ct}$ method. The primers were shown in Table 2.

\section{Table 1 Sequence information}

\begin{tabular}{ll}
\hline Name & Sequences \\
\hline InCRNA-LET siRNA-1 & Sense: 5'-GUCUGAUGUAUCCACCCAUTT-3' \\
& Antisense: 5'-AUGGGUGGAUACAUCAGACTT-3' \\
InCRNA-LET siRNA-2 & Sense: 5'-GUGCAUGUGGUAGGUUAGATT-3' \\
& Antisense: 5'-UCUAACCUACCACAUGCACTT-3' \\
InCRNA-LET shRNA & Sense: 5'-GATCCGGTCTGATGTATCCACCCA \\
& TTTCAAGAGAATGGGTGGATACATCAGACT \\
& TTTTA-3' \\
& Antisense: 5'-AGCTTAAAAAGTCTGATGTATCCA \\
& CCCATTCTCTTGAATGGGTGATACATCA \\
& GACCG-3' \\
\hline
\end{tabular}


Table 2 Primers for quantitative real-time PCR

\begin{tabular}{ll}
\hline Gene name & Primer sequences \\
\hline IncRNA-LET & Forward: 5'-AGCGTTTACTTCGTTGTTGT-3' \\
& Reverse: 5'-CAGAATGGAAATACTGGAGC-3' \\
B-actin & Forward: 5'-CACTGTGCCCATCTACGAGG-3' \\
& Reverse: 5'-TAATGTCACGCACGATTTCC-3' \\
miR-373-3p & Forward: 5'-GGCGGAAGTGCTTCGATTTT-3' \\
& Reverse: 5'-GTGCAGGGTCCGAGGTATTC-3' \\
U6 & Forward: 5'-GCTTCGGCAGCACATATACT-3' \\
& Reverse: 5'-GTGCAGGGTCCGAGGTATTC-3' \\
\hline
\end{tabular}

\section{Cell cycle analysis}

The 786-O and 769-P cells were firstly cultured in RPMI1640 medium supplemented with $10 \%$ FBS, respectively. Then, the same batch of cells $\left(4 \times 10^{5} /\right.$ well $)$ were seeded onto 6-well plates and cultured in RPMI-1640 medium containing $10 \%$ FBS. 786-O cells were transiently transfected with IncRNA-LET OV or OV NC vector, or cotransfected with IncRNA-LET OV and miR-373-3p mimics or mimics NC. The 769-P cells were transiently transfected with lncRNA-LET siRNA or siRNA NC. After $48 \mathrm{~h}$, cells were collected and fixed in ice-cold 70\% ethanol for $12 \mathrm{~h}$ at $4{ }^{\circ} \mathrm{C}$, and then incubated with $25 \mu \mathrm{l}$ propidium iodide (PI) and $10 \mu \mathrm{l}$ RNase A (Beyotime, China) for $30 \mathrm{~min}$ at $37{ }^{\circ} \mathrm{C}$ in the dark. Cell cycle distribution was analyzed using flow cytometer.

\section{EdU assay}

Cells were cultured with cell medium containing a final concentration of $10 \mu \mathrm{M}$ EdU (Keygen, China) for $2 \mathrm{~h}$. They were then fixed in $4 \%$ paraformaldehyde for $15 \mathrm{~min}$, and incubated with $0.5 \%$ Triton X-100 for $20 \mathrm{~min}$ at room temperature. Cells were subsequently washed twice with PBS containing 3\% BSA and then reacted with Click-iT for $30 \mathrm{~min}$. The nuclei were stained with Hoechst 33342 (1:2000, Keygen, China) for $15 \mathrm{~min}$. Finally, the images were captured under fluorescence microscopy and the EdU-positive cells were calculated.

\section{Western blot analysis}

Total proteins were obtained using RIPA buffer (Beyotime, China), and mitochondrial proteins were extracted with Mitochondrial Protein Extraction Kit (BOSTER, China). Then, protein concentrations were determined via a BCA Protein Assay Kit (Beyotime, China). Proteins were separated through SDS-PAGE and transferred to
PVDF membranes. After blocking in 5\% BSA, the membranes were subsequently incubated with primary antibodies, including Cyclin D1 (1:500; \#2978, CST, USA), Cyclin E (1:500; \#20808, CST, USA), Bax (1:5000; 505992-Ig, Proteintech, China), Bcl-2 (1:500; 12789-1-AP, Proteintech, China), Cytochrome $C$ (1:5000; ab133504, Abcam, UK), Dickkopf-1 (DKK1) (1:1000; 21112-1-AP, Proteintech, China), tissue inhibitor of metalloproteinase-2 (TIMP2) (1:500; A1558, Abclonal, China), and $\beta$-actin (1:2000; 60008-1-Ig, Proteintech, China) overnight at $4{ }^{\circ} \mathrm{C}$. Afterwards, the membranes were incubated with the secondary antibody (1:10,000; SA00001-1 or SA00001-2, Proteintech, China) for $40 \mathrm{~min}$ at $37^{\circ} \mathrm{C}$. Signals were detected with enhanced chemiluminescence (7 Sea biotech, China).

\section{Cell apoptosis detection}

Cells were collected and centrifuged at $1000 \mathrm{~g}$ for $5 \mathrm{~min}$. Then, the cells in $195 \mu$ l binding buffer were incubated with $5 \mu \mathrm{l}$ AnnexinV-FITC and $10 \mu \mathrm{l}$ PI for $15 \mathrm{~min}$ at room temperature in the dark according to the manufacturer's instruction (Beyotime, China). Cell apoptosis was analyzed by flow cytometer.

\section{Caspase activity assay}

The activities of caspase- 3 and caspase- 9 were analyzed with corresponding Caspase Assay Kits (Beyotime or Solarbio, China). Briefly, proteins were extracted from cells and then qualified with Bradford Protein Assay Kit (Beyotime, China). Subsequently, samples were incubated with the caspase substrate for $24 \mathrm{~h}$ at $37^{\circ} \mathrm{C}$. The absorbance was determined at $405 \mathrm{~nm}$.

\section{JC-1 assay}

Cells were obtained and centrifuged at $550 \mathrm{~g}$ for $5 \mathrm{~min}$. Then, the cells were resuspended in $500 \mu \mathrm{l} \mathrm{JC-1}$ staining working solution (Beyotime, China). After incubation for $20 \mathrm{~min}$ in the incubator at $37^{\circ} \mathrm{C}$, cells were centrifuged at $600 \mathrm{~g}$ for $5 \mathrm{~min}$ and washed twice with $1 \times \mathrm{JC}-1$ staining buffer, and resuspended with $500 \mu \mathrm{l} 1 \times \mathrm{JC}-1$ staining buffer. JC-1 aggregate was measured via the flow cytometer.

\section{Hematoxylin-eosin (HE) staining}

The tumor tissues were fixed with $4 \%$ paraformaldehyde, embedded with paraffin and then cut into 5- $\mu$ m sections. Afterwards, the sections were deparaffinized and rehydrated before being stained with hematoxylin (Solarbio, China) and eosin (Sangon, China). The staining was visualized under a microscope. 


\section{TUNEL staining}

The tumor tissues were fixed with $4 \%$ paraformaldehyde and $5-\mu \mathrm{m}$ sections were embedded in paraffin, followed by deparaffinization and rehydration. The TUNEL-positive cells were labeled by Label Solution with Enzyme solution for $60 \mathrm{~min}$ at $37^{\circ} \mathrm{C}$ in the dark, and then these sections were incubated with converter-peroxidase (POD) according to the manufacturer's protocol. Afterwards, hematoxylin (Solarbio, China) was used for the counterstaining of cell nuclei. The analysis of apoptotic cells was conducted and images were taken under a microscope.

\section{Immunofluorescence analysis}

Cells were fixed in $4 \%$ paraformaldehyde for $15 \mathrm{~min}$ and incubated with $0.1 \%$ Triton X-100 (Beyotime, China) for $30 \mathrm{~min}$. Additionally, tumor tissues were fixed in $4 \%$ paraformaldehyde, embedded with paraffin and cut into $5-\mu \mathrm{m}$ sections. Then, the sections were incubated with goat serum to block nonspecific binding. The sections were subsequently incubated with anti-Ki67 antibody (1:50, Proteintech, China) or anti-Cytochrome $C$ antibody (1:100, proteintech, China) overnight at $4{ }^{\circ} \mathrm{C}$. After washing thrice with PBS, the sections were incubated with Cy3 goat anti-rabbit IgG (1:200, Beyotime, China) and counterstained with DAPI (Biosharp, China). The results were analyzed under a fluorescence microscope.

\section{Luciferase reporter assay}

$293 \mathrm{~T}$ cells were seeded onto 12 -well plates. The partial lncRNA-LET sequences containing wild-type (WT) and mutant (MUT) binding sites for miR-373-3p were synthesized and subcloned into pmirGLO luciferase reporter vectors. The $293 \mathrm{~T}$ cells were transfected with the luciferase reporter constructs together with miR-373-3p mimics or mimics NC with Lipofectamine 2000. After a 48-h incubation, the transfected cells were collected and the luciferase activity analysis was conducted.

\section{In vivo xenograft mouse model}

Male 5-week-old BALB/c nude mice were obtained from BEIJING HFK BIOSCIENCE Co., LTD (China). All animal experiments were conducted according to the Guideline for the Care and Use of Laboratory Animals and approved by the Ethics Committee of the First Affiliated Hospital of Zhengzhou University. Mice acclimated for 1 week and then randomly assigned to four groups $(\mathrm{n}=6$ /group): EV group, lncRNA-LET group, shRNA Ctrl group, lncRNA-LET shRNA group. $5 \times 10^{6}$ cells stably expressing EV, lncRNA-LET, shRNA Ctrl or lncRNALET shRNA vectors were subcutaneously injected in the right fore-flank of each nude mouse. Then, the size of the tumor was recorded every 3 days for 21 days. Finally, the mice were sacrificed and tumor tissues were photographed. The tumor volume was calculated with the equation volume $\left(\mathrm{mm}^{3}\right)=$ length $\times$ width $^{2} / 2$.

\section{Statistical analysis}

All date were analyzed with GraphPad Prism version 7.0 and presented as mean \pm SD. The two-tailed paired and unpaired Student's t-test was used to test for significant differences between two groups. One-way ANOVA analysis followed by Tukey's test was used to analyze the multi-sample analysis. p value less than 0.05 was considered statistically significant.

\section{Results}

LncRNA-LET expression is down-regulated in ccRCC tissues To examine the clinical significances of lncRNA-LET in ccRCC tissues, we conducted quantitative real-time PCR. The lncRNA-LET expression level was significantly decreased in ccRCC tissues compared with matched adjacent non-tumor tissues (Fig. 1a). On the contrary, miR373-3p expression was higher in ccRCC tissues (Fig. 1b).

\section{LncRNA-LET arrests cell cycle at $\mathrm{G} 1$ stage in ccRCC cells}

The basal expression levels of lncRNA-LET in three ccRCC cancer cell lines were first determined via quantitative real-time PCR. The lowest and highest lncRNALET expression were observed in 786-O cells and 769-P cells, respectively (Fig. 2a). Next, IncRNA-LET overexpression plasmid was transfected into 786-O cells, while two lncRNA-LET siRNAs were transfected into 769-P cells. The overexpression and knockdown efficiencies were confirmed via quantitative real-time PCR in these two cell lines (Fig. 2b). EdU incorporation assays demonstrated that IncRNA-LET inhibited ccRCC cell
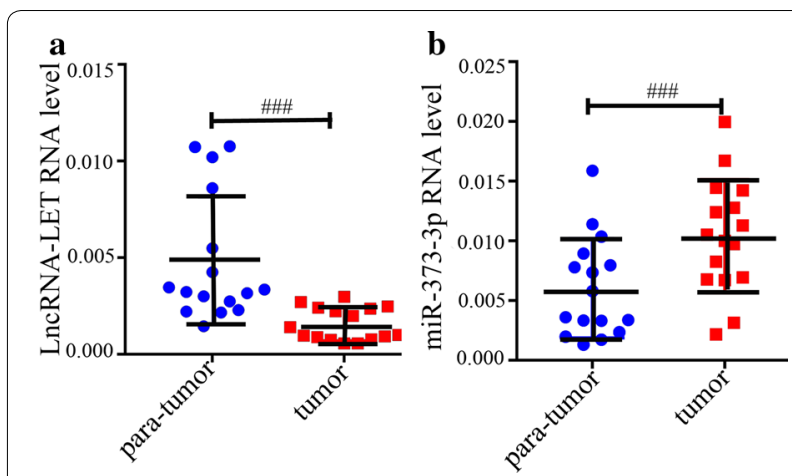

Fig. 1 LnCRNA-LET expression is down-regulated in CCRCC tissues. The expression levels of LnCRNA-LET (a) and miR-373-3p (b) were detected using quantitative real-time PCR in $C C R C C$ tissues and matched adjacent non-tumor tissues. $n=16,{ }^{\# \#} p<0.001$. cCRCC clear cell renal cell carcinoma 

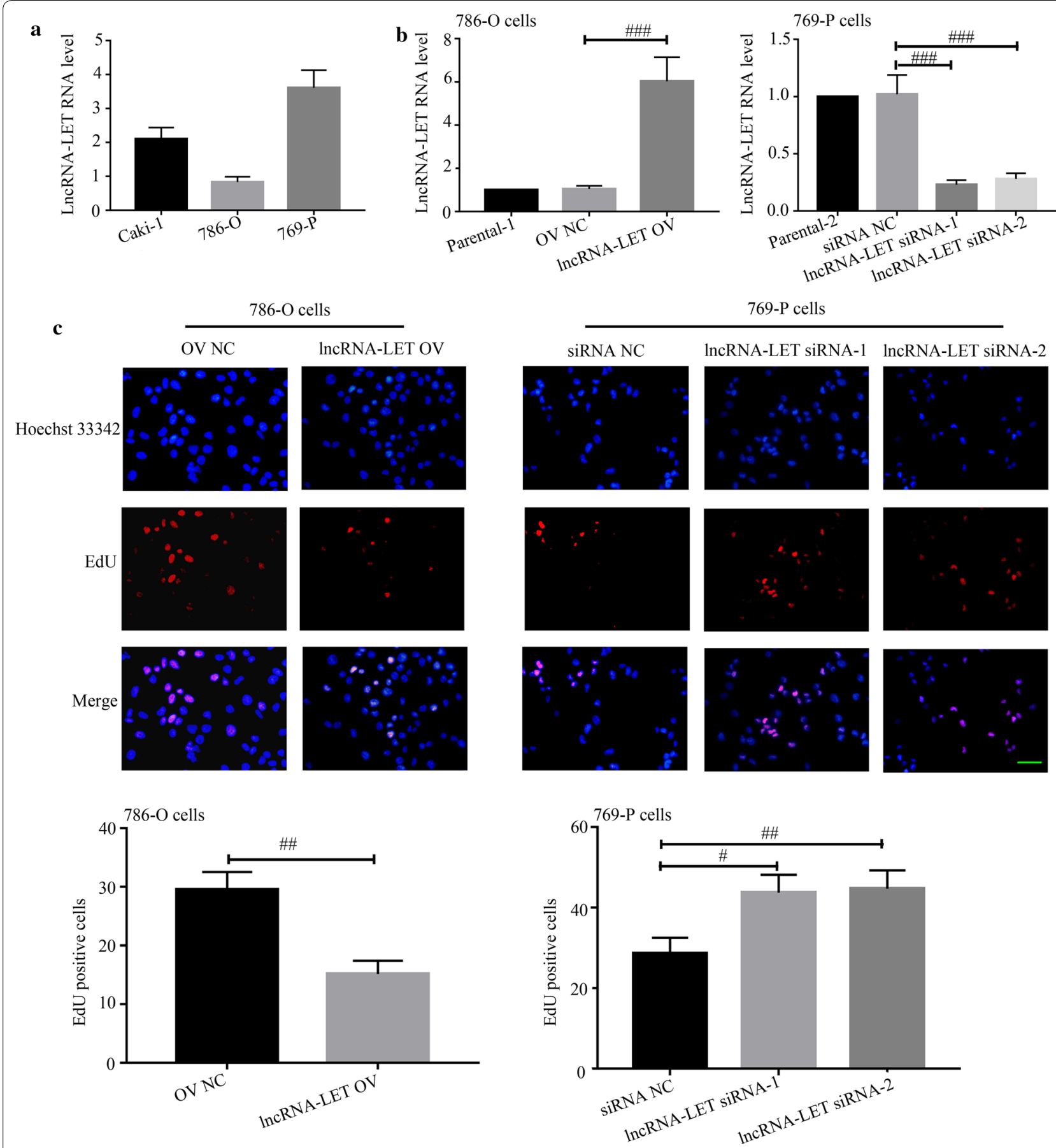

Fig. 2 LnCRNA-LET arrests cell proliferation in CCRCC cells. a LnCRNA-LET level was measured in Caki-1, 786-O, 769-P cells by quantitative real-time PCR. $\mathbf{b}$ The level of IncRNA-LET was assayed in IncRNA-LET overexpression 786-O cells or IncRNA-LET knockdown 769-P cells via quantitative real-time PCR. c Cell proliferation was detected via EdU staining. Scale bars, $50 \mu \mathrm{m} .{ }^{\#} \mathrm{p}<0.05,{ }^{\# \#} \mathrm{p}<0.01,{ }^{\# \#} \mathrm{p}<0.001$. ccRCC clear cell renal cell carcinoma

proliferation (Fig. 2c). Cell cycle progression detection revealed that IncRNA-LET overexpression caused a dramatic accumulation in G1-phase and reduction in
S-phase of 786-O cells, whereas IncRNA-LET silencing accelerated cell cycle of 769-P cells to S-phase (Fig. 3a). Moreover, IncRNA-LET overexpression down-regulated 

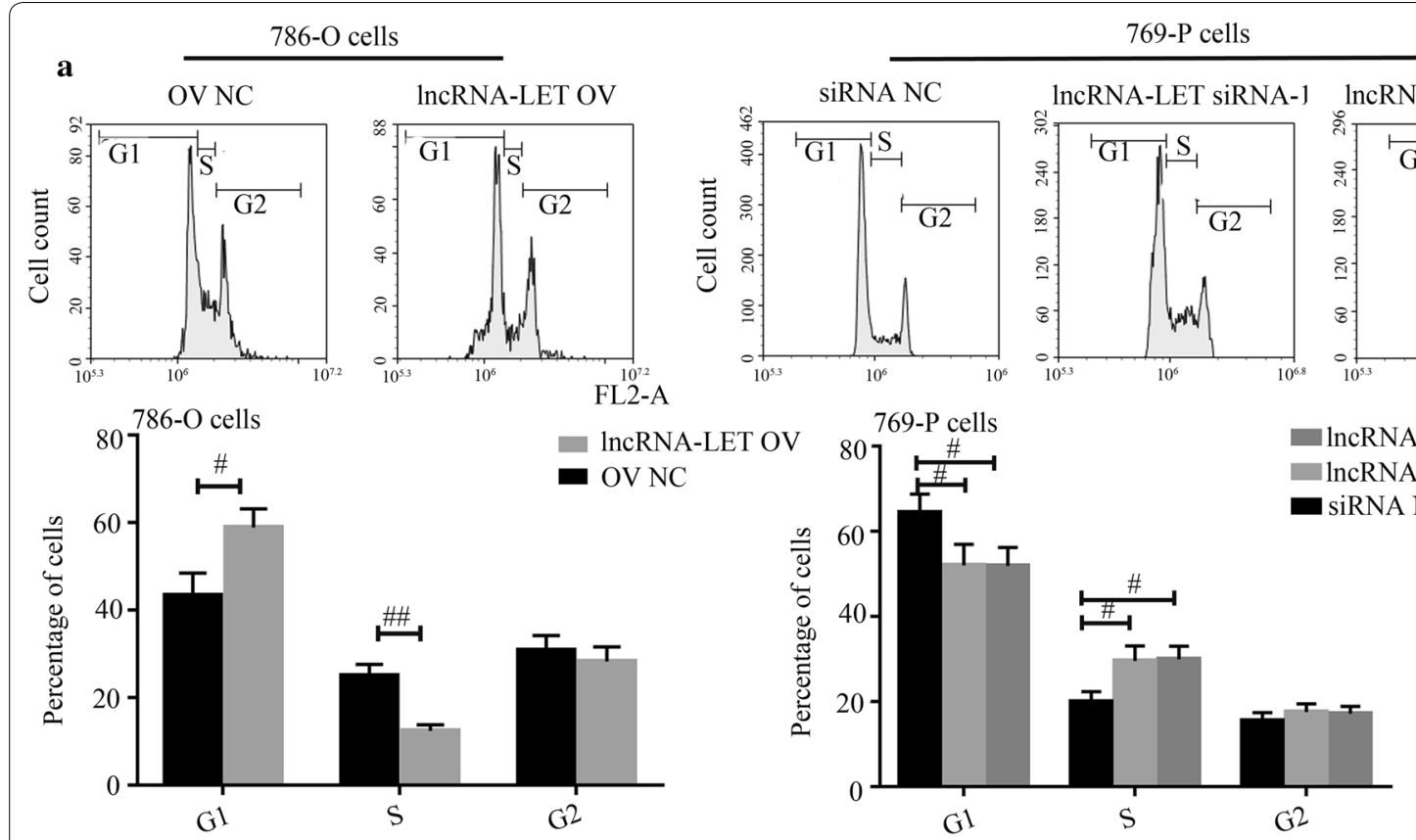

b
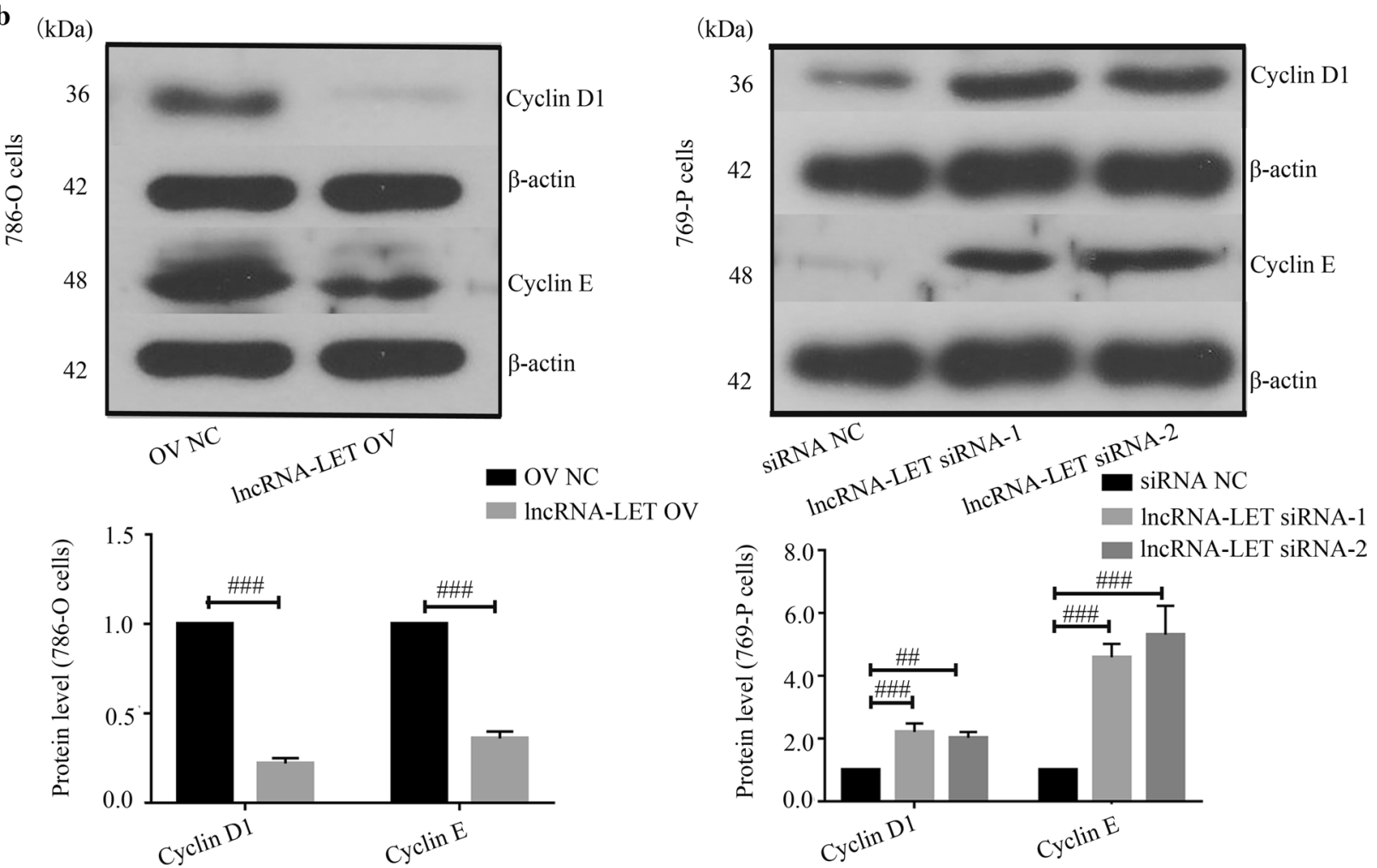

Fig. 3 LncRNA-LET arrests cell cycle in ccRCC cells. a The flow cytometry was used to analyze cell cycle phase distribution. b The Cyclin D1 and Cyclin E protein levels were analyzed with western blot analysis. ${ }^{\#} \mathrm{p}<0.01, \# \# \mathrm{p}<0.001$. cCRCC clear cell renal cell carcinoma

the expression of Cyclins D1 and E in 786-O cells, while lncRNA-LET knockdown up-regulated their expression in 769-P cells (Fig. 3b). These findings suggest that lncRNA-LET suppresses the proliferation and arrests cell cycle progress of ccRCC cells.

\section{LncRNA-LET promotes cell apoptosis in cCRCC cells}

Results from flow cytometry indicated that lncRNALET overexpression significantly promoted cell apoptosis while lncRNA-LET silencing suppressed cell apoptosis (Fig. 4a). Meanwhile, lncRNA-LET increased 


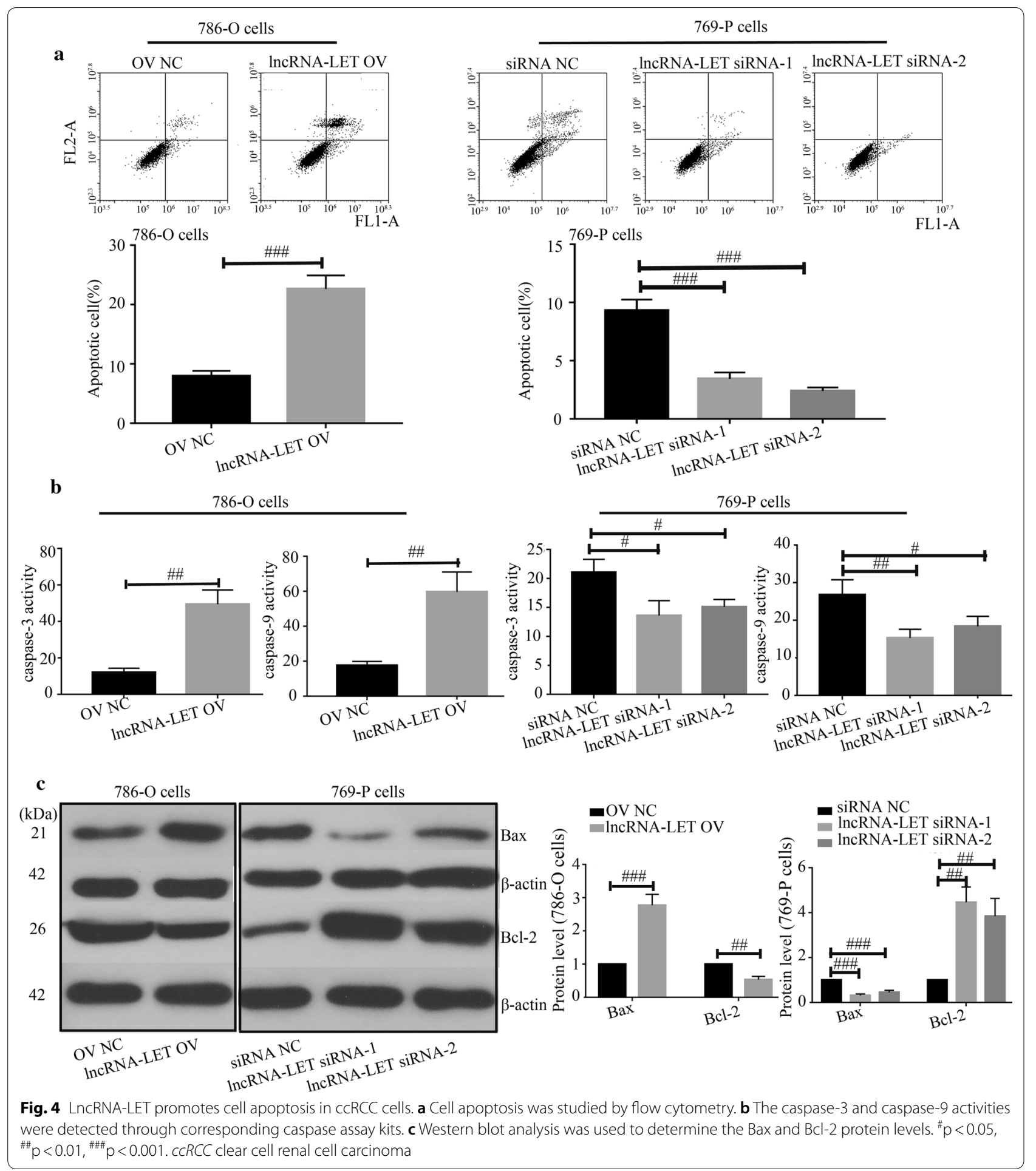

caspase- 3 and caspase- 9 activities (Fig. 4b), up-regulated Bax expression and reduced Bcl-2 expression (Fig. 4c) in 786-O cells. Data from JC-1 assay illustrated that lncRNA-LET increased the ratio of green/monomeric forms of JC-1 in ccRCC cells (Fig. 5a). Further western blot analysis confirmed that lncRNA-LET led to the release of Cytochrome $C$ from mitochondria (Fig. 5b). Immunofluorescence also showed that IncRNA-LET overexpression significantly facilitated cytosolic translocation of Cytochrome $C$ and lncRNA-LET silencing 


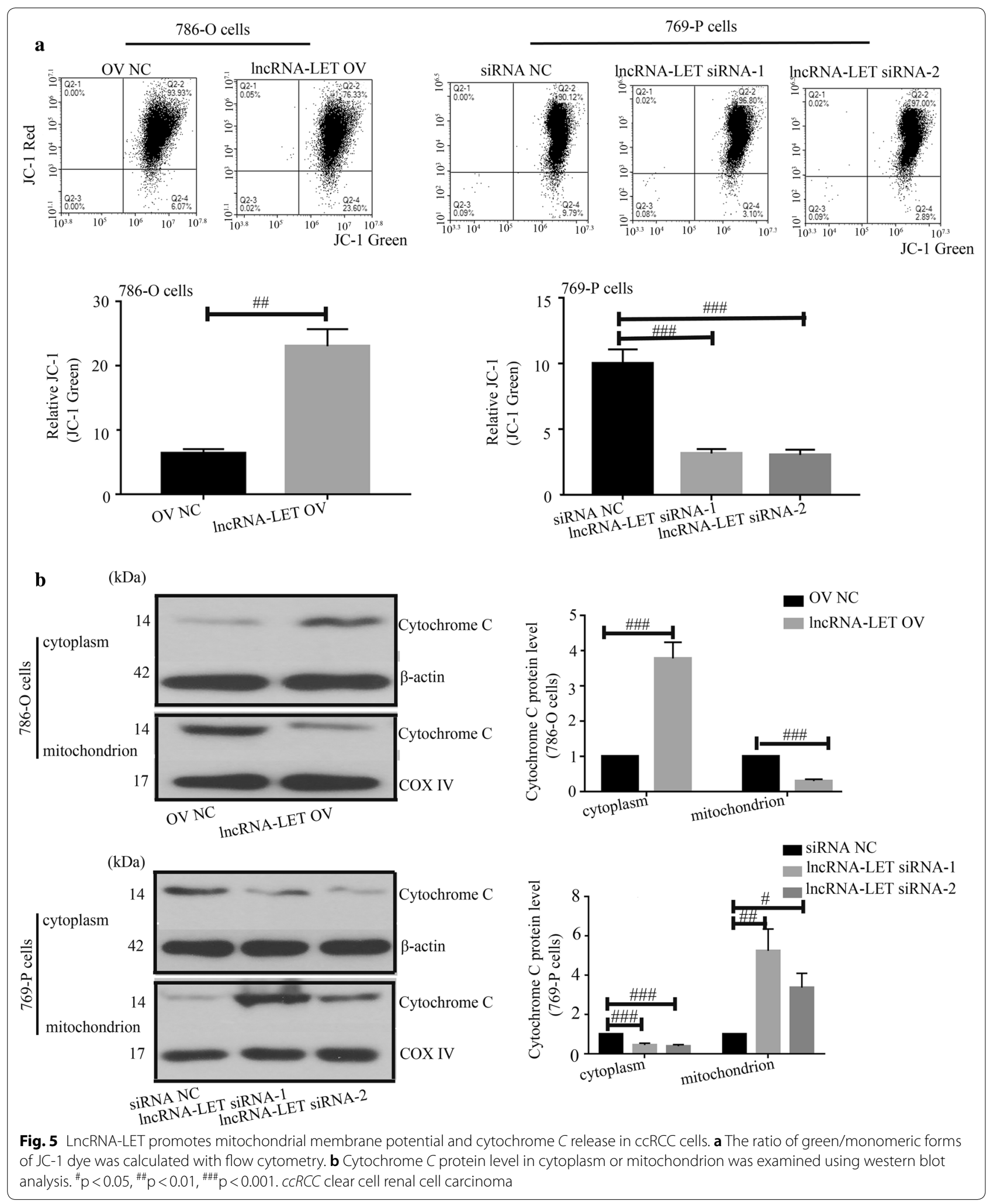




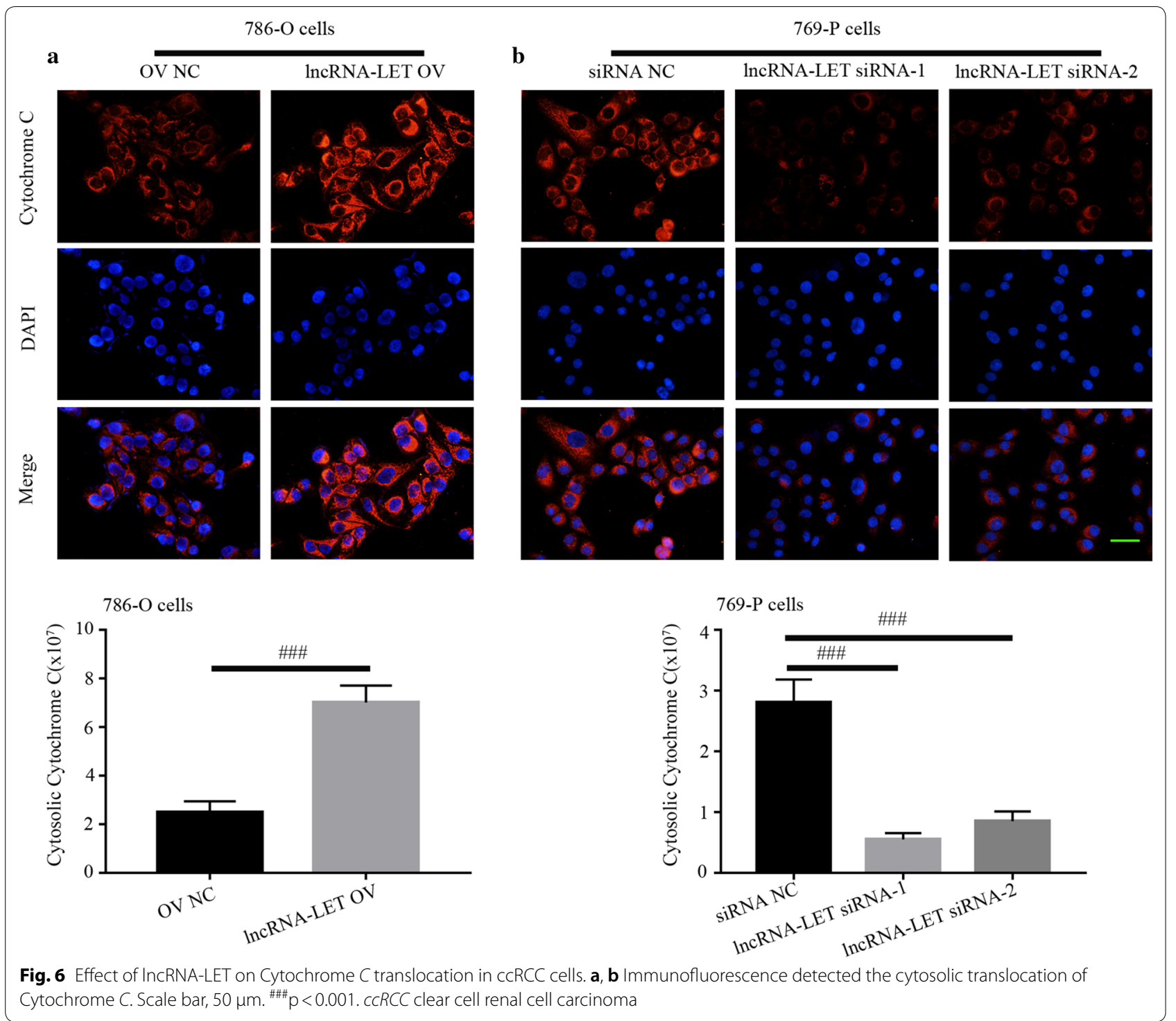

inhibited its translocation in ccRCC cells (Fig. 6a, b). The data reveal that lncRNA-LET promotes cell apoptosis in ccRCC cells possibly.

\section{LncRNA-LET targets miR-373-3p to regulate ccRCC cell growth}

We further explored the mechanism underlying the role of IncRNA-LET in ccRCC. We hypothesized that IncRNA-LET bound to miR-373-3p to regulate development of ccRCC. As shown in Fig. 1b, the miR-373-3p expression level was increased in ccRCC tissues. Then, we carried out miR-373-3p overexpression or knockdown in ccRCC cells (Fig. 7a). Quantitative real-time PCR revealed that miR-373-3p mimics down-regulated lncRNA-LET expression, whereas miR-373-3p inhibitor up-regulated the lncRNA-LET expression level (Fig. 7b). MiR-373-3p was predicted to bind to lncRNA-LET (Fig. 7c, d). Luciferase report assay confirmed the interaction between lncRNA-LET and miR373-3p (Fig. 7e). Further, we found that lncRNA-LET positively regulated DKK1 and TIMP2 expression in ccRCC cells (Fig. 7f). However, miR-373-3p mimics reduced the DKK1 and TIMP2 expression caused by lncRNA-LET (Fig. 8a). Additionally, miR-373-3p mimics alleviated the effects of IncRNA-LET overexpression on cell cycle and apoptosis (Fig. 8b, c). These data indicate that IncRNA-LET inhibits cell growth of ccRCC cells through targeting miR-373-3p. 

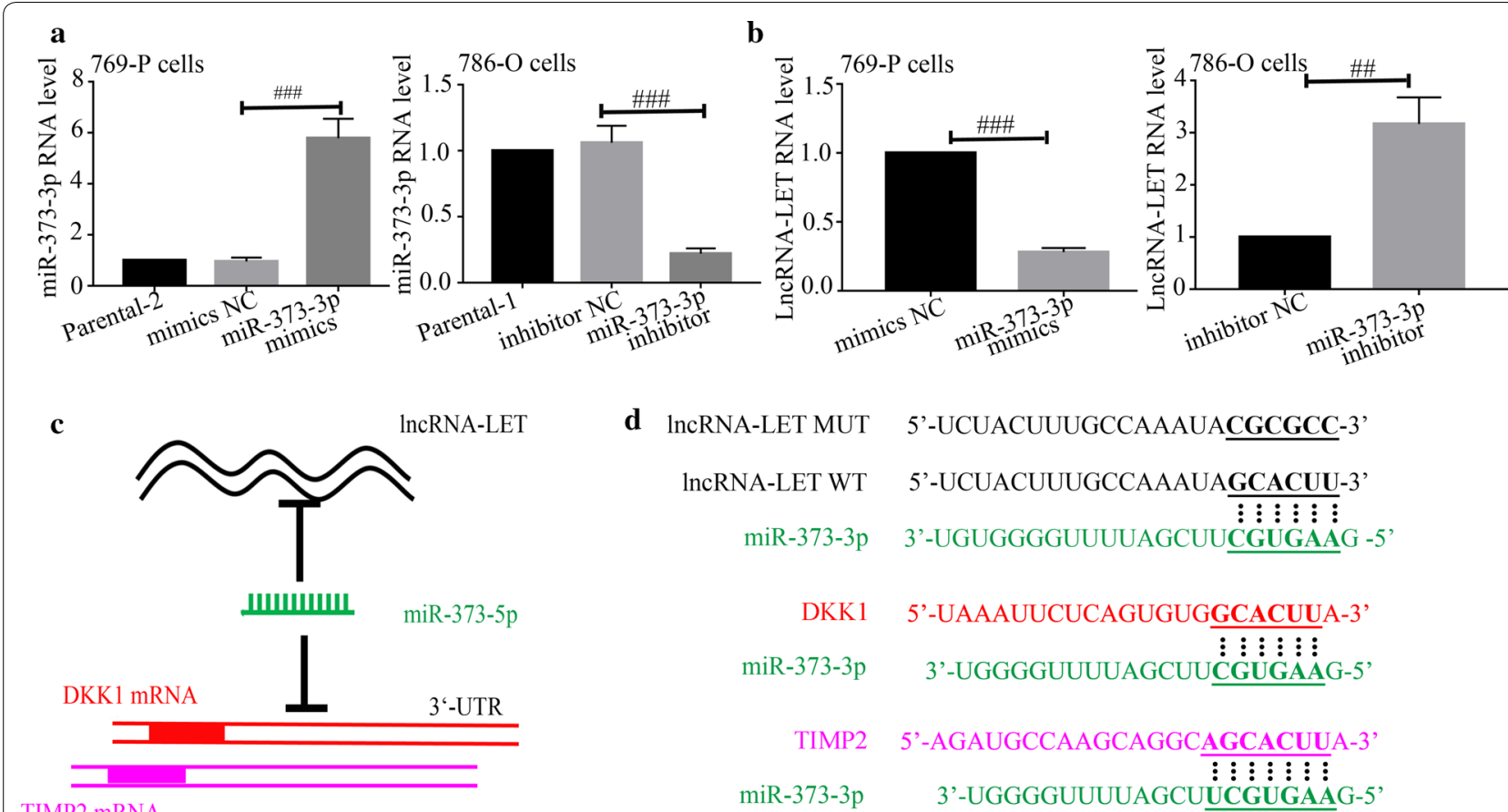

TIMP2 mRNA

f

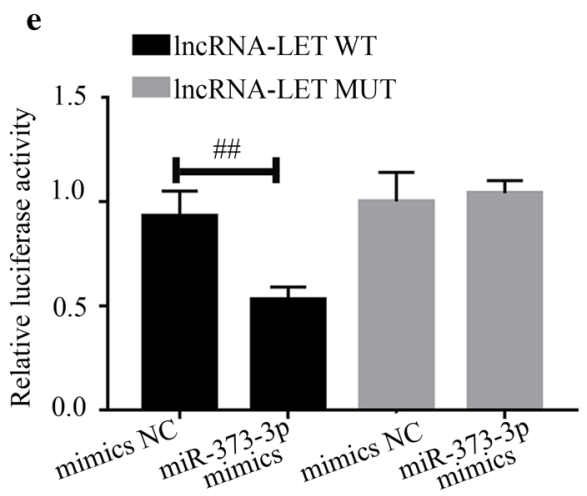

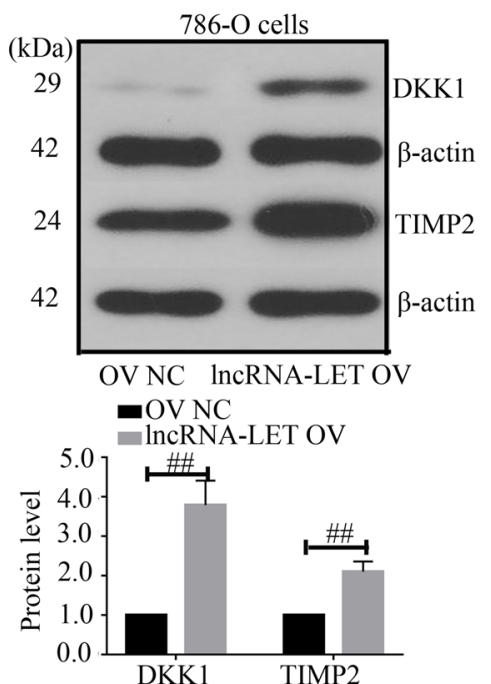

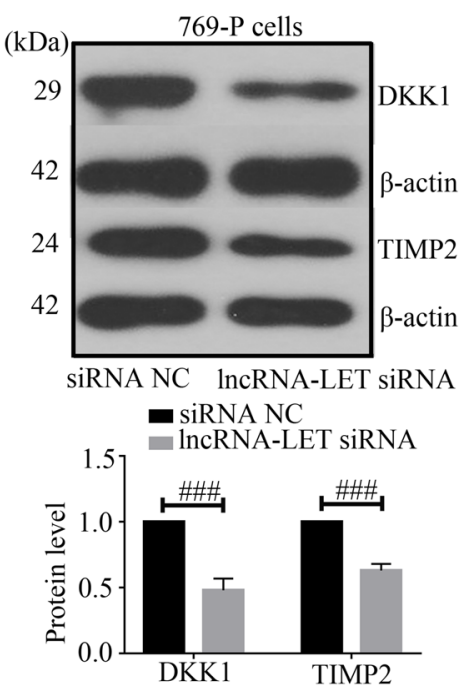

Fig. 7 LnCRNA-LET is involved in cell growth of ccRCC cells by targeting miR-373-3p. a MiR-373-3p level was assayed in ccRCC cells with miR-373-3p mimics or inhibitor via quantitative real-time PCR. $\mathbf{b}$ LnCRNA-LET level was assayed in miR-373-3p mimics or inhibitor ccRCC cells via quantitative real-time PCR. c Schematic diagram: IncRNA-LET (black) function as a target of miR-373-3p (green). MiR-373-3p was indicated to bind with DKK1 (red) and TIMP2 (burgandy). ORF was filled with rectangles. $\mathbf{d}$ The binding sites between IncRNA-LET and miR-373-3p, miR-373-3p and DKK1, miR-373-3p and TIMP2 were predicted. e The relationship between IncRNA-LET and miR-373-3p was demonstrated through luciferase reporter assay. f DKK1 and TIMP2 protein levels were examined with western blot analysis. ${ }^{\#} p<0.01, \# \# p<0.001$. ccRCC clear cell renal cell carcinoma, DKK1 Dickkopf-1, TIMP2 tissue inhibitor of metalloproteinase-2, mimics NC negative control mimics

\section{LncRNA-LET inhibits tumor growth in vivo}

In order to evaluate the function of IncRNA-LET in tumor growth in vivo, we stably overexpressed lncRNALET in 786-O cells or knocked lncRNA-LET down in
769-P cells. These stably transfected cells were subcutaneously injected into nude mice. LncRNA-LET led to reduction of tumor volume (Fig. 9a, b). Further HE staining, TUNEL staining and Ki67 immunostaining results 

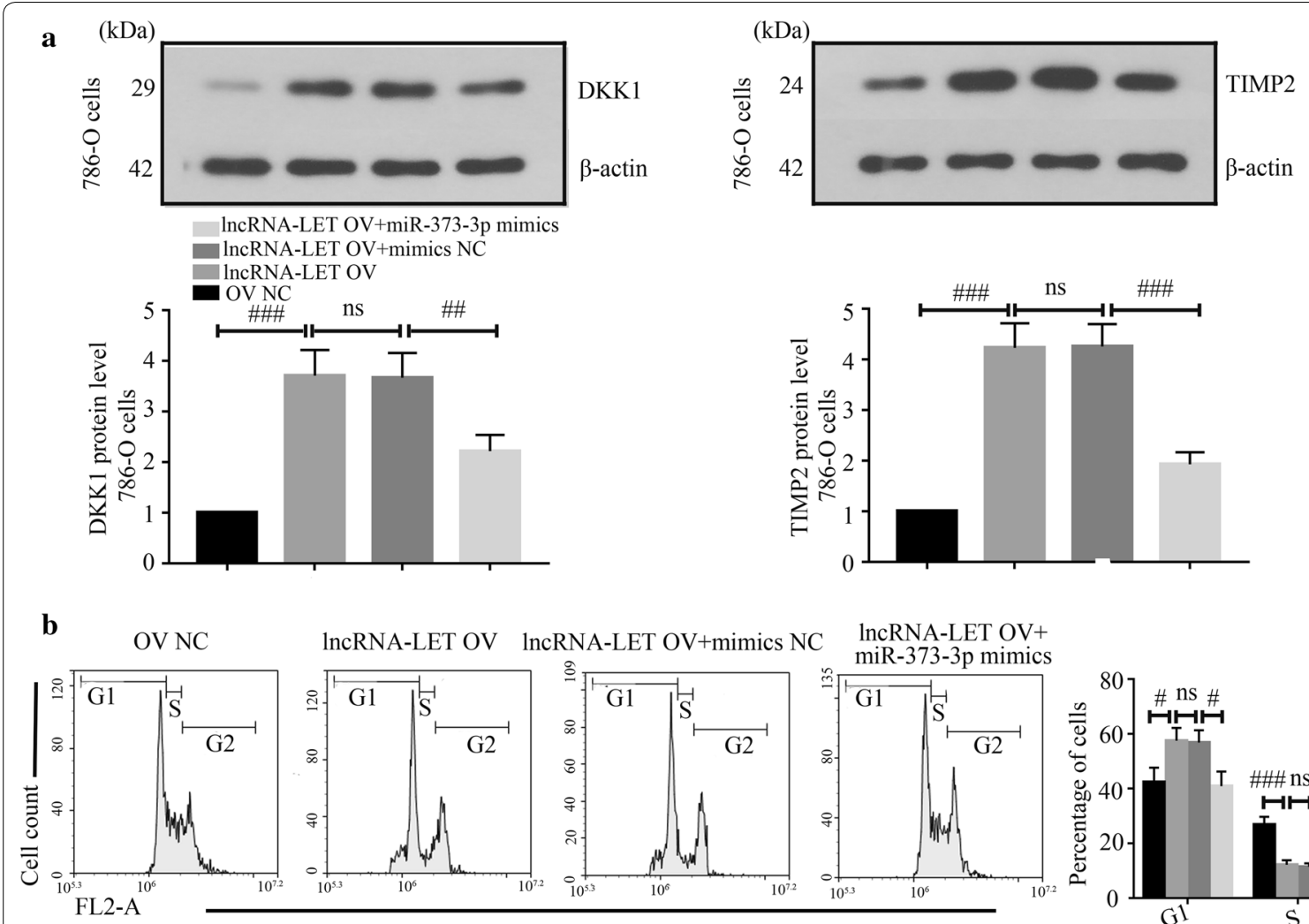

b $786-\mathrm{O}$ cells

c $\quad$ OV NC

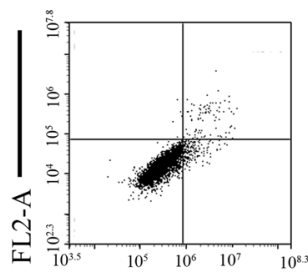

FL1-A
IncRNA-LET OV IncRNA-LET OV+mimics NC

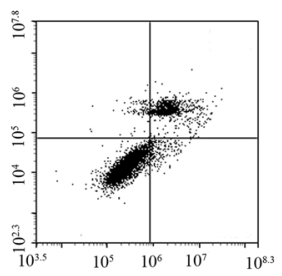

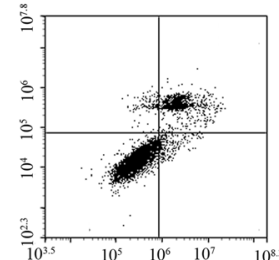

786-O cells
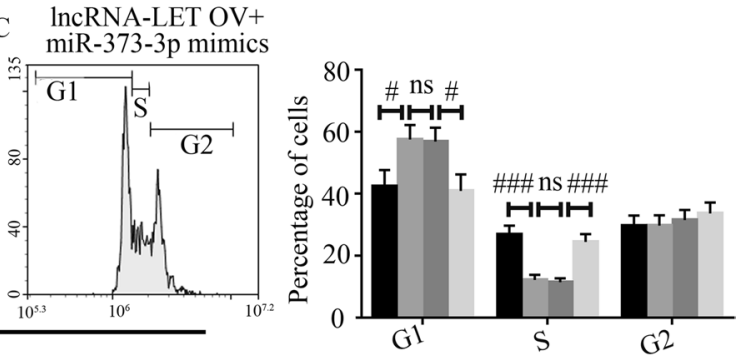

IncRNA-LET OV+ miR-373-3p mimics

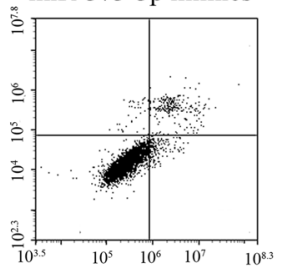

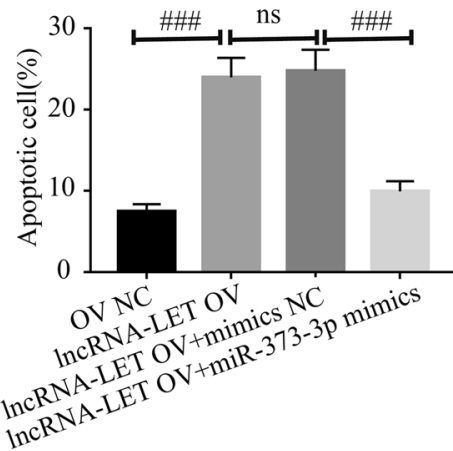

Fig. 8 MiR-373-3p mimics alleviate the effects of IncRNA-LET overexpression on cell cycle and apoptosis. a Western blot analysis was used to measure the DKK1 and TIMP2 protein levels. Cell cycle phase distribution (b) and cell apoptosis (c) were analyzed through flow cytometry. ${ }^{\# \#} \mathrm{p}<0.01$, $\# \#$ $<0.001$. ns, ccRCC clear cell renal cell carcinoma, mimics NC negative control mimics

showed that lncRNA-LET increased apoptosis, and suppressed cell proliferation (Fig. 9c-e). These results indicate that lncRNA-LET functions similarly in vivo and in vitro.

\section{Discussion}

In this study, low IncRNA-LET was found in ccRCC tissues compared with matched adjacent non-tumor tissues. LncRNA-LET induced cell cycle arrest and apoptosis of
ccRCC in vitro and inhibited the growth of xenografts in vivo. Further study showed lncRNA-LET performed its role in ccRCC by targeting miR-373-3p.

LncRNAs are reported to regulate various biological processes. They can contribute to the tumor progression or act as tumor-suppressors in ccRCC [12, 23-25]. It was reported that the low IncRNA-LET level was correlated to the poor prognosis of patients with lung cancer or gastric cancer [26, 27]. Wu et al. [17] showed a low lncRNALET level in the serum of ccRCC patients and regarded 


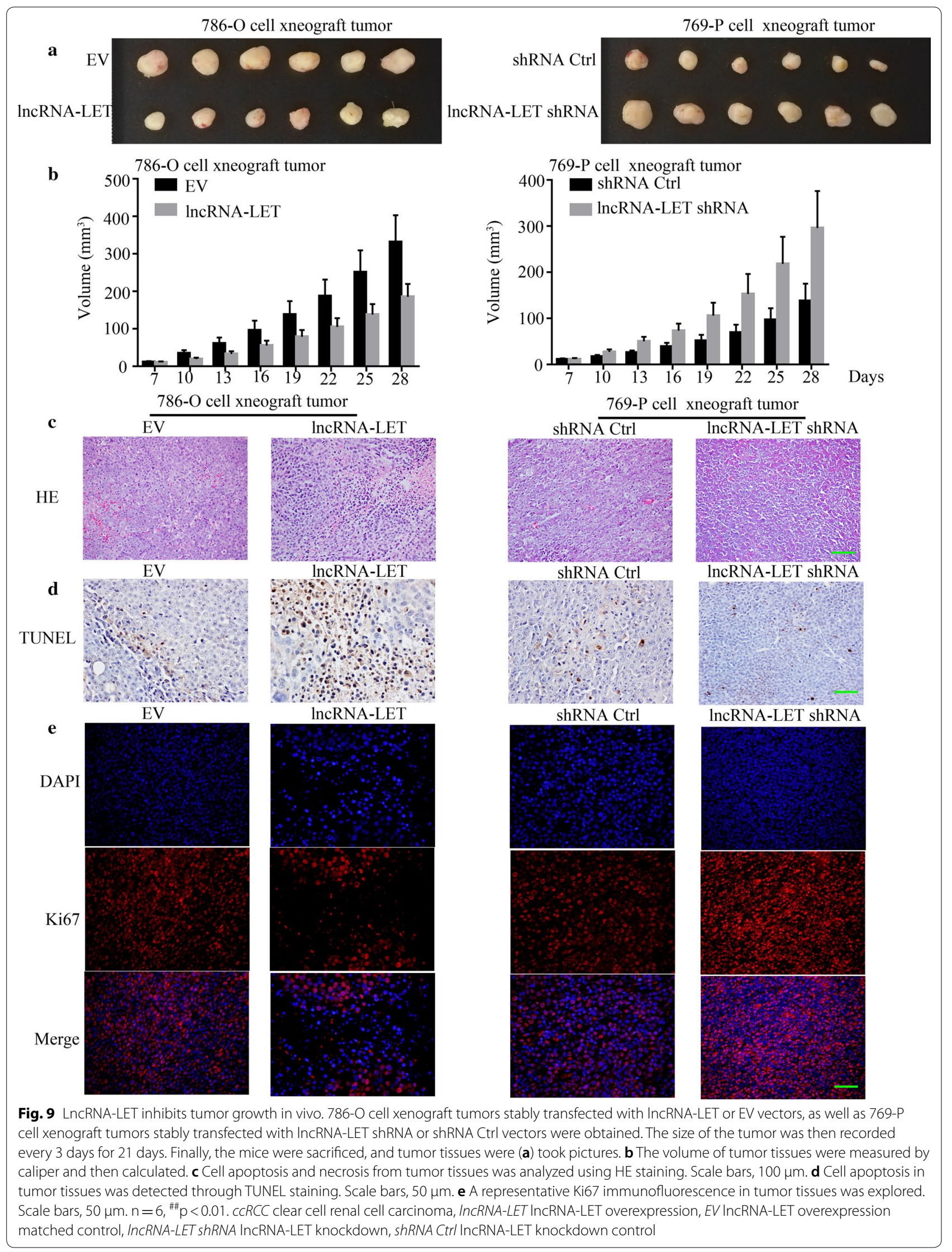


it as highly indicative of ccRCC diagnosis. In this study, we confirmed a low lncRNA-LET level in ccRCC tissues, which was consistent with the report of Wu et al. However, the role of lncRNA-LET in the growth of ccRCC is still unclear and needs further exploration.

In our study, lncRNA-LET inhibited the growth of ccRCC, both in vitro and in vivo. Cell cycle contributes to the growth of cells, and cyclins are key drivers of cell cycle. The growth-inhibitory effect of IncRNA-LET was accompanied with cell cycle arrest, which was further confirmed by declines in cyclins. Besides, lncRNA-LET also induced apoptosis in ccRCC cells, which was further confirmed by increased activities of caspase- 3 and caspase-9. Interestingly, we found that InCRNA-LET increased the level of Bax and decreased the level of Bcl2. As the ratio of $\mathrm{Bax} / \mathrm{Bcl}-2$ contributes to the opening of mitochondrial permeability transition pore, it indicated that the induction of apoptosis by lncRNA-LET may be associated with mitochondria-mediated apoptosis. Therefore, the mitochondrial membrane potential and release of cytochrome $C$ were detected. Our results demonstrated that IncRNA-LET modulated mitochondrial membrane potential and enhanced the release of cytochrome $C$, indicating that apoptosis of ccRCC induced by IncRNA-LET may belong to mitochondriamediated apoptosis. Additionally, we found that IncRNALET increased the levels of DKK1 and TIMP2, which are involved in the regulation of cell migration [28-30], suggesting that lncRNA-LET may also have an effect on the metastasis of RCC. More researches are needed to verify this speculation.

Furthermore, how lncRNA-LET performed its tumorsuppressor role in ccRCC was explored. Li et al. revealed that miR-373-3p promoted tumorigenesis of RCC in vitro and in vivo [22]. In our study, we identified lncRNA-LET as a direct target of miR-373-3p. Interestingly, we found that the levels of DKK1 and TIMP2, which are two verified targets of miR-373-3p, were increased by IncRNALET. These results prompt us that lncRNA-LET may also modulate the expression of miR-373-3p target genes. Thus, rescue experiments were performed in our study. The results showed that miR-373-3p down-regulated the lncRNA-LET-induced increase of DKK1 and TIMP2 levels, and reversed the effects of IncRNA-LET on cell cycle and apoptosis. These results indicate that IncRNA-LET may perform its tumor-suppressor role in ccRCC cells through regulating the expression of miR-373-3p target genes. In 2011, Salmena et al. proposed a concept of competing endogenous RNA (ceRNA) [31] that targets of microRNA, such as mRNAs, lncRNAs and pseudogenes, can inversely target microRNAs using their microRNA response elements, thus modulating the expression of target genes and resulting in their various roles. We hypothesize that lncRNA-LET may act as a tumorsuppressor in ccRCC through a ceRNA pattern. As the ceRNA network is a large-scale regulatory network, there must be other microRNAs which lncRNA-LET may target to perform its role in ccRCC. However, our study focused on only miR-373-3p, there remains a large scale of microRNAs which can be targeted by lncRNA-LET. Hence, further explorations are needed to reveal the mechanism underlying lncRNA-LET.

\section{Conclusions}

In the present study, lncRNA-LET repressed cell cycle, induced apoptosis and inhibited tumor growth of ccRCC by targeting miR-373-3p. We identified lncRNA-LET as a tumor-suppressor in ccRCC. The results of the present study provide a potential biomarker and therapeutic target for ccRCC treatment.

\section{Abbreviations \\ ccRCC: clear cell renal cell carcinoma; IncRNA: long non-coding RNA; DKK1: Dickkopf-1; TIMP2: tissue inhibitor of metalloproteinase-2; FBS: fetal bovine serum; NC: negative control; EV: empty control; PI: propidium iodide.}

\section{Acknowledgements}

Not applicable.

\section{Authors' contributions}

$Z Y, J D$ and $B Q$ conceived and designed the experiments. ZY, JD, LW and YJ performed the experiments and analyzed the data. ZY, JD and BQ contributed to the writing of the manuscript. All authors read and approved the final manuscript.

\section{Funding}

This study was supported by a Grant from the National Natural Science Foundation of China (No. 81370869).

\section{Availability of data and materials}

The datasets used and analyzed during the current study are available from the corresponding author on reasonable request.

\section{Ethics approval and consent to participate}

This study was approved by the Ethics Committee of the First Affiliated Hospital of Zhengzhou University, and conferred to Declaration of Helsinki.

\section{Consent for publication}

Not applicable.

\section{Competing interests}

The authors declare that they have no competing interests.

\section{Author details}

${ }^{1}$ Department of Urology, The First Affiliated Hospital of Zhengzhou University, 1 East Jianshe Road, Zhengzhou 450052, People's Republic of China. ${ }^{2}$ Department of Pathology and Pathophysiology, The Academy of Medical Sciences, Zhengzhou University, Zhengzhou 450001, People's Republic of China.

Received: 13 May 2019 Accepted: 31 October 2019

Published online: 21 November 2019 


\section{References}

1. Capitanio U, Bensalah K, Bex A, Boorjian SA, Bray F, Coleman J, Gore JL, Sun M, Wood C, Russo P. Epidemiology of renal cell carcinoma. Eur Urol. 2019;75(1):74-84

2. Siegel RL, Miller KD, Jemal A. Cancer statistics, 2018. CA Cancer J Clin. 2018;68(1):7-30.

3. Siegel R, Ma J, Zou Z, Jemal A. Cancer statistics, 2014. CA Cancer J Clin. 2014;64(1):9-29.

4. Klatte T, Stewart GD. Renal cell carcinoma: standards and controversies. World J Urol. 2018;36(12):1889-90.

5. Li JR, Ou YC, Yang CK, Wang SS, Chen CS, Ho HC, Cheng CL, Yang CR, Chen CC, Wang SC, et al. The impact of local intervention combined with targeted therapy on metastatic renal cell carcinoma. Anticancer Res. 2018;38(9):5339-45.

6. George S, Rini Bl, Hammers HJ. Emerging role of combination immunotherapy in the first-line treatment of advanced renal cell carcinoma: a review. JAMA Oncol. 2018;5(3):411-21.

7. Hsieh JJ, Purdue MP, Signoretti S, Swanton C, Albiges L, Schmidinger M, Heng DY, Larkin J, Ficarra V. Renal cell carcinoma. Nat Rev Dis Primers. 2017:3:17009.

8. Capitanio U, Montorsi F. Renal cancer. Lancet. 2016;387(10021):894-906

9. Cech TR, Steitz JA. The noncoding RNA revolution-trashing old rules to forge new ones. Cell. 2014;157(1):77-94.

10. Bartel DP. MicroRNAs: genomics, biogenesis, mechanism, and function. Cell. 2004;116(2):281-97.

11. Yang F, Huo XS, Yuan SX, Zhang L, Zhou WP, Wang F, Sun SH. Repression of the long noncoding RNA-LET by histone deacetylase 3 contributes to hypoxia-mediated metastasis. Mol Cell. 2013;49(6):1083-96.

12. Wang C, Wang G, Zhang Z, Wang Z, Ren M, Wang X, Li H, Yu Y, Liu J, Cai L, et al. The downregulated long noncoding RNA DHRS4-AS1 is protumoral and associated with the prognosis of clear cell renal cell carcinoma. OncoTargets Ther. 2018;11:5631-46.

13. Jin P, Wang J, Liu Y. Downregulation of a novel long non-coding RNA, LOC389332, is associated with poor prognosis and tumor progression in clear cell renal cell carcinoma. Exp Ther Med. 2017;13(3):1137-42.

14. Liu B, Pan CF, He ZC, Wang J, Wang PL, Ma T, Xia Y, Chen YJ. Long noncoding RNA-LET suppresses tumor growth and EMT in lung adenocarcinoma. Biomed Res Int. 2016;2016:4693471.

15. Wang PL, Liu B, Xia Y, Pan CF, Ma T, Chen YJ. Long non-coding RNA-Low expression in tumor inhibits the invasion and metastasis of esophageal squamous cell carcinoma by regulating p53 expression. Mol Med Rep. 2016;13(4):3074-82

16. Zhang Z, Cheng J, Wu Y, Qiu J, Sun Y, Tong X. LncRNA HOTAIR controls the expression of Rab22a by sponging miR-373 in ovarian cancer. Mol Med Rep. 2016;14(3):2465-72.

17. Wu Y, Wang YQ, Weng WW, Zhang QY, Yang XQ, Gan HL, Yang YS, Zhang $\mathrm{PP}$, Sun $\mathrm{MH}$, Xu MD, et al. A serum-circulating long noncoding RNA signature can discriminate between patients with clear cell renal cell carcinoma and healthy controls. Oncogenesis. 2016;5:e192.

18. Chen Z, Lin J, Wu S, Xu C, Chen F, Huang Z. Up-regulated miR-548k promotes esophageal squamous cell carcinoma progression via targeting long noncoding RNA-LET. Exp Cell Res. 2018;362(1):90-101.
19. Zhuang J, Shen L, Yang L, Huang X, Lu Q, Cui Y, Zheng X, Zhao X, Zhang D, Huang $R$, et al. TGFbeta1 promotes gemcitabine resistance through regulating the LncRNA-LET/NF90/miR-145 signaling axis in bladder cancer. Theranostics. 2017;7(12):3053-67.

20. Weng J, Zhang H, Wang C, Liang J, Chen G, Li W, Tang H, Hou J. miR373-3p targets DKK1 to promote EMT-induced metastasis via the Wnt/ beta-catenin pathway in tongue squamous cell carcinoma. Biomed Res Int. 2017;2017:6010926.

21. Hu W, Liu Q, Pan J, Sui Z. MiR-373-3p enhances the chemosensitivity of gemcitabine through cell cycle pathway by targeting CCND2 in pancreatic carcinoma cells. Biomed Pharmacother. 2018;105:887-98.

22. Li Y, Zhang D, Wang J. MicroRNA373 promotes tumorigenesis of renal cell carcinoma in vitro and in vivo. Mol Med Rep. 2017;16(5):7048-55.

23. Dong D, Mu Z, Wei N, Sun M, Wang W, Xin N, Shao Y, Zhao C. Long non-coding RNA ZFAS1 promotes proliferation and metastasis of clear cell renal cell carcinoma via targeting miR-10a/SKA1 pathway. Biomed Pharmacother. 2019;111:917-25.

24. Qu Y, Xiao H, Xiao W, Xiong Z, Hu W, Gao Y, Ru Z, Wang C, Bao L, Wang K, et al. Upregulation of MIAT regulates LOXL2 expression by competitively binding MiR-29c in clear cell renal cell carcinoma. Cell Physiol Biochem. 2018;48(3):1075-87.

25. Wang G, Zhang ZJ, Jian WG, Liu PH, Xue W, Wang TD, Meng YY, Yuan C, Li HM, Yu YP, et al. Novel long noncoding RNA OTUD6B-AS1 indicates poor prognosis and inhibits clear cell renal cell carcinoma proliferation via the Wnt/beta-catenin signaling pathway. Mol Cancer. 2019;18(1):15.

26. Li S, Zhao H, Li J, Zhang A, Wang H. Downregulation of long non-coding RNA LET predicts poor prognosis and increases Notch signaling in nonsmall cell lung cancer. Oncotarget. 2018;9(1):1156-68.

27. Zhou B, Jing XY, Wu JQ, Xi HF, Lu GJ. Down-regulation of long non-coding RNA LET is associated with poor prognosis in gastric cancer. Int J Clin Exp Pathol. 2014:7(12):8893-8.

28. Zhou J, Jiang J, Wang S, Xia X. DKK1 inhibits proliferation and migration in human retinal pigment epithelial cells via the Wnt/beta-catenin signaling pathway. Exp Ther Med. 2016;12(2):859-63.

29. Yi N, Liao QP, Li ZH, Xie BJ, Hu YH, Yi W, Liu M. RNA interference-mediated targeting of DKK1 gene expression in Ishikawa endometrial carcinoma cells causes increased tumor cell invasion and migration. Oncol Lett. 2013;6(3):756-62.

30. Han Q, Zhang W, Meng J, Ma L, Li A. LncRNA-LET inhibits cell viability, migration and EMT while induces apoptosis by up-regulation of TIMP2 in human granulosa-like tumor cell line KGN. Biomed Pharmacother. 2018:100:250-6.

31. Salmena L, Poliseno L, Tay Y, Kats L, Pandolfi PP. A ceRNA hypothesis: the Rosetta Stone of a hidden RNA language? Cell. 2011;146(3):353-8.

\section{Publisher's Note}

Springer Nature remains neutral with regard to jurisdictional claims in published maps and institutional affiliations.

Ready to submit your research? Choose BMC and benefit from

- fast, convenient online submission

- thorough peer review by experienced researchers in your field

- rapid publication on acceptance

- support for research data, including large and complex data types

- gold Open Access which fosters wider collaboration and increased citations

- maximum visibility for your research: over 100M website views per year

At $\mathrm{BMC}$, research is always in progress.

Learn more biomedcentral.com/submissions 